J. Dairy Sci. 99:3295-3304

http://dx.doi.org/10.3168/jds.2015-10273

(C) American Dairy Science Association ${ }^{\circledR}, 2016$.

\title{
Proteomic tracking of hydrothermal Maillard and redox modification in lactoferrin and $\beta$-lactoglobulin: Location of lactosylation, carboxymethylation, and oxidation sites
}

\author{
Jolon M. Dyer, ${ }^{,} \dagger \ddagger \S^{1}$ Stefan Clerens, ${ }^{*} \ddagger$ Anita Grosvenor, ${ }^{*}$ Ancy Thomas, ${ }^{*}$ Chris Callaghan, ${ }^{*}$ \\ Santanu Deb-Choudhury, ${ }^{*}$ and Stephen Haines* \\ ${ }^{*}$ Food \& Bio-Based Products, AgResearch Lincoln Research Centre, Lincoln 7608, New Zealand \\ †Riddet Institute at Massey University, Palmerston North 4474, New Zealand \\ ¥Biomolecular Interaction Centre, University of Canterbury, Christchurch 8041, New Zealand \\ $\S$ Wine, Food \& Molecular Biosciences, Lincoln University, Lincoln 7608, New Zealand
}

\section{ABSTRACT}

Lactoferrin and $\beta$-lactoglobulin are important protein components of mammalian milk. Maillard reactions, as well as redox chemistry, are of particular interest for dairy products because they are known to occur during common processing steps, notably heating procedures such as pasteurization. Using a redox proteomics approach, we characterized AA residue side-chain modification across a range of heating times and with or without the specific addition of lactose, to both map the key modification sites within these proteins and evaluate their sensitivity to process-induced modification. Heating in the presence of lactose resulted in significant Maillard modification (both lactosylation and carboxymethylation) to both bovine lactoferrin and $\beta$-lactoglobulin. Notably, Lys47, a key residue in the bioactive peptide lactoferricin, was particularly susceptible to modification. Lactoferrin appeared to be fairly robust to hydrothermal treatment, with relatively low levels of oxidative modification observed. In contrast, $\beta$-lactoglobulin was susceptible to significant oxidative modification under hydrothermal treatment, with the range and type of modifications observed suggesting compromised nutritional value. These results have important implications for processing applications in dairy foods where retention of biological function and optimal protein quality is desired.

Key words: lactoferrin, $\beta$-lactoglobulin, Maillard reaction, redox chemistry, proteomics

Received August 17, 2015.

Accepted January 4, 2016.

${ }^{1}$ Corresponding author: jolon.dyer@agresearch.co.nz

\section{INTRODUCTION}

Lactoferrin and $\beta$-LG are important protein components of mammalian milk (Farrell et al., 2004). Lactoferrin, a globular glycoprotein of approximate molecular weight of $80 \mathrm{kDa}$ also known as lactotransferrin, is a multi-functional component of the immune system, with reported antimicrobial, antifungal, and antiviral properties (Adlerova et al., 2008). It has an important immunomodulatory role and can be found in a range of secretory fluids in addition to milk, including tears and saliva (Adlerova et al., 2008). Digestion with pepsin and chymosin, such as occurs during consumption of dairy foods, is believed to result in the release and uptake of bioactive peptides from lactoferrin (Tomita et al., 2009). $\beta$-Lactoglobulin is the major protein present in whey from cow, goat, and sheep milk, but is notably absent in human milk. It is also a globular protein with a molecular weight of approximately $18 \mathrm{kDa}$ (precursor $20 \mathrm{kDa}$, mature protein $18 \mathrm{kDa}$ ), but is yet to be robustly assigned a specific cellular or systemic function (Kontopidis et al., 2004).

Maillard chemistries can profoundly affect the color, flavor, digestibility, and nutritional value of food. They encompass a complex array of reactions, starting with the glycation of protein AA residues, with lysine being particularly susceptible, and progressing to form sugarderived protein adducts and cross-links also known as advanced glycation end products. The consequences of such chemistry can be positive, such as flavor development, or negative, such as unwanted coloration changes, and thus understanding and controlling Maillard chemistry is important in food processing. For instance, impaired nutritional value can occur due to changes in protein integrity and function through protein crosslinking mediated by glycation products, which could limit the bioavailability of the AA lysine. 
Maillard reactions are of particular interest for dairy products, as they are known to occur during common processing steps, notably heating procedures such as pasteurization (Meyer et al., 2012). Milk has a high lactose content (Cerbulis and Farrell, 1975), making it particularly susceptible to lactosylation during storage and processing (Guyomarc'h et al., 2000). The implication for dairy foods is significant, with potential changes in structure, physicochemical properties, susceptibility to proteases, nutritional value, and bioactivity. Whereas Maillard reaction products of caseins and major whey proteins have been relatively well characterized (Jing and Kitts, 2004; Aminlari et al., 2005; Meltretter et al., 2007), only very limited previous work has been done with lactoferrin (Joubran et al., 2013), and the location of modifications in these proteins is not well understood.

The effects of the Maillard reaction in the case of lactoferrin have important potential implications with respect to its use as a functional ingredient. Specific regions of lactoferrin responsible for bioactive function, for example, iron-binding and antimicrobial peptides, contain lysine. Lactosylation of these lysine residues is likely to have a profound effect on bioactivity, either altering it or eliminating activity completely. Lactosylation is an early stage Maillard product. Lactosylated residues can subsequently undergo oxidative cleavage to form protein-bound carboxymethyllysine. We here postulate that hydrothermal treatment, such as is commonly applied in milk processing and production of dairy products, leads to both lactosylation and subsequent formation of carboxymethyllysine from susceptible lysine residues. The occurrence of lactosylation in some milk proteins has been reported previously (Fogliano et al., 1998), but detailed mapping of susceptibility has not been performed.

Redox proteomics is a sub-discipline of proteomics that focuses on the characterization of often low abundance oxidative modifications to proteins. Application of redox proteomics to a range of systems has led to the development of a powerful set of mass spectrometric and bioinformatic tools, and these have been used effectively to map modifications in proteins exposed to oxidative and other insults (Dyer et al., 2006a, 2010; Grosvenor et al., 2010, 2011). In this study, we applied a redox proteomic approach to specifically characterize sites of lactosylation in lactoferrin, and performed a parallel analysis of another key whey protein, $\beta$-LG. We characterized AA residue side-chain modification across a range of heating times with or without the specific addition of lactose, to both map the key modification sites within these proteins and evaluate their sensitivity to process-induced modification.

\section{MATERIALS AND METHODS}

\section{Sample Preparation}

Disodium hydrogen orthophosphate and sodium dihydrogen orthophosphate were from BDH (Poole, UK). Bovine lactoferrin, $\beta-\mathrm{LG}$, and lactose and all other general chemicals were obtained from Sigma (St. Louis, MO). Lactoferrin and $\beta$-LG were each dissolved in PBS (10 $\mathrm{m} M, \mathrm{pH} 6.8)$ at a concentration of $0.15 \mathrm{mM}$ (11.1 $\mathrm{mg} / \mathrm{mL}$ of lactoferrin, $2.67 \mathrm{mg} / \mathrm{mL}$ of $\mathrm{LG}$ ). The solutions were heated at $55^{\circ} \mathrm{C}$ in the presence or absence of lactose $(146 \mathrm{mM})$ with agitation using a Mini LabRoller rotator (Labnet, Woodbridge, NJ) for 24, 48, 72, 96, 120, 144, and $168 \mathrm{~h}$. This resulted in a 973-fold molar ratio excess of lactose:protein, reflecting a biologically relevant lactose concentration and the lactose:substrate ratios used in Dalsgaard et al. (2007) and Meltretter et al. (2007).

\section{Proteomic Evaluation}

Enzymatic Digestion. Samples were prepared for mass spectrometric analysis by dialysis in Slide-A-Lyzer Mini dialysis units fitted with 2,000 molecular weight cutoff membranes (Thermo, Rockford, IL) against 100 $\mathrm{m} M$ ammonium bicarbonate, which was the solvent for subsequent steps. Reduction was performed with $50 \mathrm{~m} M$ Tris(2-carboxyethyl)phosphine at $56^{\circ} \mathrm{C}$ for 45 min, followed by alkylation with $360 \mathrm{mM}$ acrylamide in the dark at ambient temperature for $30 \mathrm{~min}$ and digestion using $1 \mu \mathrm{g}$ of sequencing grade porcine trypsin (Promega, Madison, WI) in 10\% acetonitrile, $50 \mathrm{mM}$ ammonium bicarbonate for $18 \mathrm{~h}$ at $37^{\circ} \mathrm{C}$.

Liquid Chromatography-Tandem Mass Spectrometry. The resulting peptides were diluted 1:500 with loading solvent ( $2 \%$ acetonitrile, $0.2 \%$ formic acid). Liquid chromatography-tandem mass spectrometry (LC-MS/MS) was carried out on an Ultimate nanoflow HPLC equipped with a Famos autosampler and Switchos column switching module (LC-Packings, Amsterdam, the Netherlands). A $10-\mu \mathrm{L}$ sample was loaded on a C18 trap column (300 $\mu \mathrm{m}$ internal diameter, $5 \mu \mathrm{m}$ particles, $300 \AA$ pore size) at a flow rate of $8 \mu \mathrm{L} / \mathrm{min}$. The trap column was then switched in line with the analytical column $(\mathrm{C} 18,20 \mathrm{~cm}, 75 \mu \mathrm{m}$ internal diameter, $5 \mu \mathrm{m}$ particles, $300 \AA$ pore size), and eluted at a flow rate of $150 \mathrm{~nL} / \mathrm{min}$, with a gradient from 2 to $55 \%$ B in 50 min. Solvent A was HPLC-grade water with $0.2 \%$ formic acid, solvent B was LCMS-grade acetonitrile with $0.2 \%$ formic acid. Using a stainless-steel nanospray needle (Proxeon, Odense, Denmark), the column outlet was directly connected to a QSTAR Pul- 
Table 1. Sequence coverage obtained for lactoferrin and $\beta-\mathrm{LG}$

\begin{tabular}{llccccc}
\hline & & \multicolumn{5}{c}{ Hours of heating at $55^{\circ} \mathrm{C}$} \\
\cline { 3 - 7 } Item & & 0 & 24 & 48 & 96 & \multirow{2}{*}{168} \\
\hline Lactoferrin & Protein only & 70.1 & 67.9 & 62.3 & 52.4 & 61.0 \\
\multirow{2}{*}{ Lactoglobulin } & With lactose & 60.9 & 52.7 & 64.8 & 54.9 & 54.8 \\
& Protein only & 71.3 & 87.6 & 88.8 & 89.3 & 91.0 \\
& With lactose & 82.0 & 84.8 & 86.5 & 87.6 & 78.1 \\
\hline
\end{tabular}

sar i mass spectrometer (Applied Biosystems, Foster City, CA), which was programmed to acquire $3 \mathrm{MS} /$ MS traces of $1+, 2+, 3+, 4+$, and $5+$ peptides per MS survey scan.

Data Analysis. Mascot Daemon (v2.2.2) was used to convert data files to peak lists (Mascot Script for Analyst v1.6b25), which were imported in ProteinScape v2.1 (Bruker Daltonik, Bremen, Germany). Peptide/ protein identification was performed from ProteinScape using an in-house Mascot server (v2.2.0.6; Matrix Science, London, UK). The following global search parameters were used: taxonomy Bos taurus; enzyme semitrypsin; MS and MS/MS mass tolerance 0.2 Da; up to 2 missed cleavages; fixed cysteine modification with propionamide. Several specific Maillard product searches including a selection of variable modifications were conducted, as well as searches for oxidations, deamidation, methylation, and N-terminal carbamyl formation. Proteinscape ProteinExtractor settings were as follows: peptide score threshold 20; at least one peptide with a score higher than 35. Peptides and proteins with a Mascot score higher than 35 and 50, respectively, were automatically accepted. After combination of all results for each sample, data were exported to Microsoft Excel for further processing and interpretation.

\section{RESULTS AND DISCUSSION}

To characterize and locate protein residue sites susceptible to molecular modification, we incubated preparations of lactoferrin and $\beta-\mathrm{LG}$ with and without lactose at $55^{\circ} \mathrm{C}$ for a range of times selected to evaluate both the development and retention of modifications $(24,48,72,96,120,144$, and $168 \mathrm{~h})$. Lactose is present in milk and throughout the processing and preparation of a range of dairy ingredients and prepared foods. Additionally, milk products are often subjected to a range of temperatures in their production, transport, and storage. Temperatures in the range 50 to $60^{\circ} \mathrm{C}$ have been shown to promote Maillard chemistry, and lactoferrin has been shown to be relatively structurally stable in this temperature range (Hurrell et al., 1983; Van Boekel, 1998; Thomsen et al., 2005).
After reduction, alkylation, and enzymatic digestion of the protein, we analyzed the resultant peptide samples using LC-MS/MS. The sequence coverages obtained for the samples are summarized in Table 1. Sequence coverage can be used as a broad indicator of protein modification, with increasing cross-link formation tending to result in decreased sequence coverage. Interestingly, we observed a general trend of decreasing sequence coverage with increasing incubation times for lactoferrin, with slightly lower levels in the presence of lactose. On the other hand, the sequence coverage of $\beta$-LG generally increased with incubation time. These differences in sequence coverage likely relate to the competing processes of crosslink formation (inhibiting digestion) and protein backbone cleavage (enhancing digestion), and may indicate the formation of differing relative amounts of these modification types for these 2 proteins (Davies, 1996; Friedman, 1999).

\section{Maillard Modification}

We performed proteomic Maillard modification profiling on all samples, specifically searching for lactosylation and carboxymethylation, which result in modified AA residue side-chain products and are therefore good indicators of Maillard chemistry. The chemistry of protein lactosylation and subsequent oxidative cleavage to produce carboxymethyllysine residues is summarized in Figure 1 (Brock et al., 2003; Czerwenka et al., 2006). It should also be noted that these modifications are precursors for further more complex Maillard modification, ultimately resulting in advanced glycation end product formation (Poulsen et al., 2013; Villaverde and Estévez, 2013). In all cases, we also identified the corresponding unmodified peptide, indicating that modification of any particular site did not proceed to completion under the conditions investigated.

Lactoferrin. We characterized 3 distinct lactosylation and 2 carboxymethylation sites in lactoferrin as summarized in Table 2.

The major site of both lactosylation and carboxymethylation in lactoferrin was within the tryptic peptide K.KLGAPSITCVR.R, with lactosylation occurring on 
Table 2. Maillard products observed in lactoferrin when heated at $55^{\circ} \mathrm{C}$ for $0,24,48,96$, or $168 \mathrm{~h}$ with or without added lactose ${ }^{1}$

\begin{tabular}{|c|c|c|c|c|c|c|c|c|c|c|c|c|}
\hline Residue & Sequence & Modification & \multicolumn{5}{|c|}{ Lactoferrin } & \multicolumn{5}{|c|}{ Lactoferrin + lactose } \\
\hline Lysine 47 & $\underline{\text { KLGAPSITCVR }}$ & $\begin{array}{l}\text { Lactosylation } \\
\text { Carboxymethyl }\end{array}$ & & & & & & & $\begin{array}{l}\sqrt{V} \\
\sqrt{ }\end{array}$ & $\sqrt{V}$ & $\begin{array}{l}\sqrt{ } \\
\sqrt{ }\end{array}$ & $\begin{array}{l}\sqrt{ } \\
\sqrt{ }\end{array}$ \\
\hline Lysine 329 & IPSKVDSALYLGSR & Lactosylation & & & & & & & $\sqrt{ }$ & $\sqrt{ }$ & $\sqrt{ }$ & \\
\hline Lysine 627 & AAHVKQVLLHQQALFGK & $\begin{array}{l}\text { Lactosylation } \\
\text { Carboxymethyl }\end{array}$ & & & & & & & $\sqrt{ }$ & $\sqrt{ }$ & $\sqrt{ }$ & $\sqrt{ }$ \\
\hline
\end{tabular}

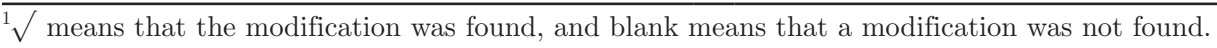

the lysine at position 47 (Lys47) in the protein primary sequence. The samples incubated with lactose at 24,48 , 96 , and $168 \mathrm{~h}$ contained lactosylated variants of this peptide, but unheated samples $(0 \mathrm{~h})$ and those without added lactose did not. Importantly, this peptide is a component of the lactoferrin-derived bioactive peptide lactoferricin, which is a known potent antibacterial peptide, and also has a range of other putative bioactive functions including anti-viral, anti-tumor, and immunological properties (Gifford et al., 2005; Baker and Baker, 2012).

Lactoferricin has the full residue sequence FKCRRWQWRMKKLGAPSITCVRRAFA. The Lys 47 (highlighted) was highly susceptible to Maillard<smiles>[Z]NC(CCCCN)C(C)=O</smiles><smiles>[Z]NC(CCCCNCC(=O)O)C(=O)O</smiles>

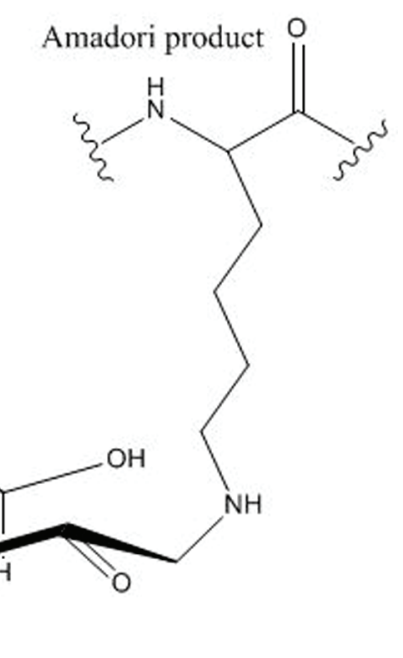

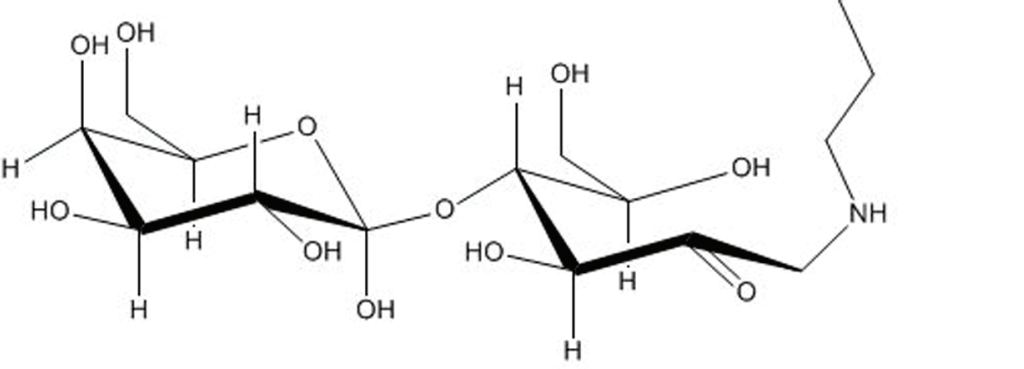

Figure 1. Schematic summary of lysine residue lactosylation and carboxymethylation (for additional details, please refer to Xu et al., 2013, and Badoud et al., 1990). 
modification and was characterized with both lactosylation and carboxymethylation modifications. This susceptibility to modification when heated in the presence of lactose is likely to have a significant effect on the antimicrobial and other activities of lactoferricin (Hoek et al., 1997), and therefore needs to be carefully considered in the processing and formulation of dairy products where retention of functionality is desired.

In addition, we observed 2 other sites of lactosylation for lactoferrin. These were at Lys627 in the tryptic peptide R.AAHVKQVLLHQQALFGK.N and Lys329 in the peptide R.IPSKVDSALYLGSR.Y (lactosylation sites highlighted). Both these lactosylations occurred in multiple samples: Lys627 at 24 and $48 \mathrm{~h}$, and Lys329 at 24, 48, and $96 \mathrm{~h}$. Lactosylation of Lys329 has also been observed in processed whey and milk fat globule extract by Renzone et al. (2015). We expect that these early-stage Maillard modifications will also have effects on the biological function and chemical and physical properties of lactoferrin and release of its encoded bioactive peptides (Moscovici et al., 2014; Joubran et al., 2015). We also observed carboxymethylation of one of these sites, Lys627, in all samples heated with added lactose.

When considering these residue sites that are highly susceptible to Maillard modification in relation to the 3-dimensional native structure of bovine lactoferrin, it is noteworthy that Lys47 and Lys627 have both been shown through structural studies to be positioned at the surface of lactoferrin, and are therefore highly exposed in both the iron-bound and non-iron-bound forms of the protein. The positive charge of Lys47 and proximal residues has a possible role in the binding of lactoferrin to bacterial cell membranes (Moore et al., 1997; Baker and Baker, 2012). Modification of this site may therefore affect this binding function. Based on these results, it appears that Lys 47 of lactoferrin has good potential utility as a sensitive marker for tracking and evaluating lactoferricin modification during ingredient processing and food preparation. In addition, Lys627 could be also used in tandem with Lys47 to support the tracking of Maillard modification in lactoferrin.

$\boldsymbol{\beta}$-Lactoglobulin. $\beta$-Lactoglobulin contained 4 distinct lactosylation and 4 carboxymethylation sites, as summarized in Table 3 . We detected 2 lactosylation sites in the samples with no added lactose, suggesting that some lactosylation has already occurred in the protein produced from milk.

The sites of Maillard modification included $\beta$-LG Lys63 and Lys107, which were lactosylated when heated in the presence of added lactose, but not in the protein samples without added lactose. Carboxymethylation of $\beta-L G$ at Lys107 also occurred in samples heated with lactose for $96 \mathrm{~h}$ and at Lys151 after heating for 168 h. Lactosylation of Lys116 and lactosylation of Lys154 occurred at a range of treatment times in samples heated both with and without added lactose. Renzone et al. (2015) also found Maillard reaction products in processed whey and milk fat globule isolate at all of these sites. We also characterized Lys154 modification in unheated samples, indicating that this modification was likely already present in the starting material. This observation suggests that the Lys154 site in $\beta$-LG is particularly sensitive to modification, with some modification occurring during the purification preparation of the protein from milk. This finding is supported by the observation of methionine oxidation (Met161) in the unheated sample, and at the residue position in close proximity to the lactosylation site (see Table 5 ).

Unlike lactoferrin, no clear function has yet been identified unequivocally for $\beta$-LG. Under physiological conditions, $\beta-\mathrm{LG}$ exists as an equilibrium mixture of monomeric and dimeric forms. It is known to bind to hydrophobic molecules and may be involved in their transport (Kontopidis et al., 2004). There is also the strong suggestion that $\beta$-LG has a primary function as a source of nutrition. Additionally, it is associated with some forms of milk allergenicity and significant

Table 3. Maillard products observed in $\beta$-LG when heated at $55^{\circ} \mathrm{C}$ for $0,24,48,96$, or $168 \mathrm{~h}$ with or without added lactose ${ }^{1}$

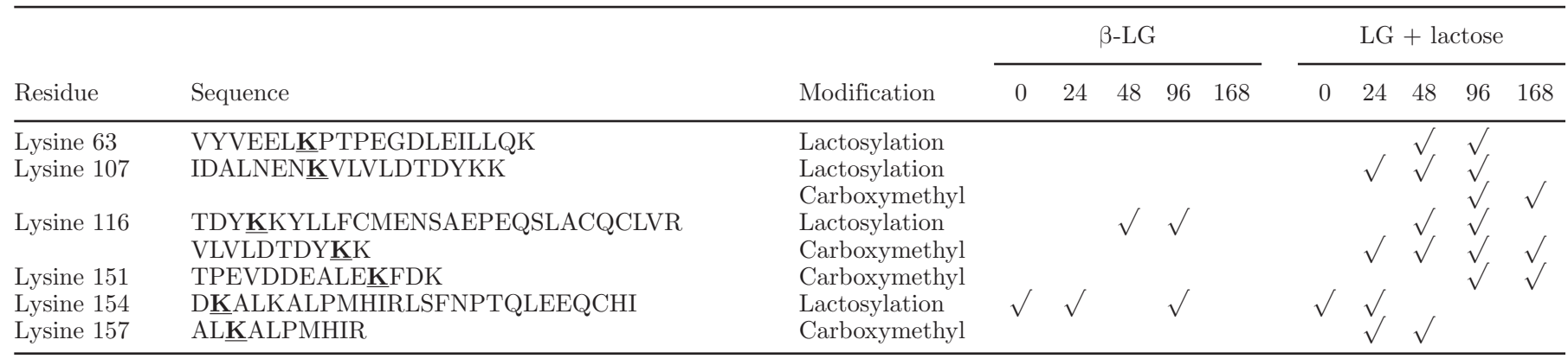

$\sqrt[1]{ }$ means that the modification was found, and blank means that a modification was not found. 
Table 4. Redox modifications observed in lactoferrin when heated at $55^{\circ} \mathrm{C}$ for $0,24,48,96$, or $168 \mathrm{~h}$ with or without added lactose ${ }^{1}$

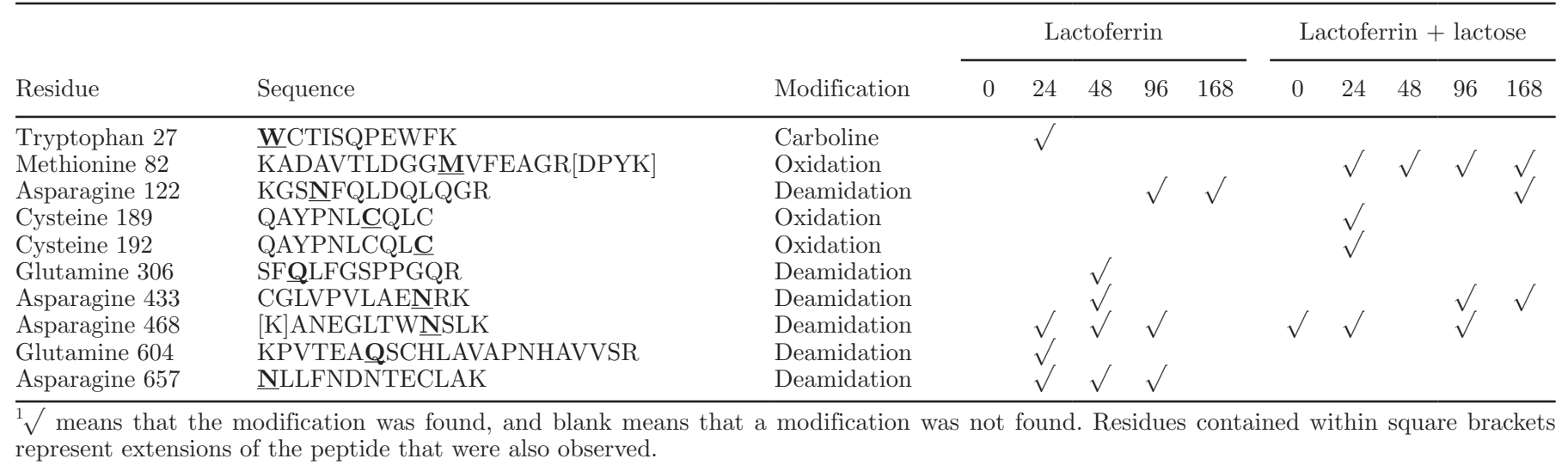

modification (enzyme-mediated crosslinking) of this protein has been shown to reduce IgE-mediated bovine milk allergenicity (Tantoush et al., 2011). In terms of the Maillard modification sites identified in this study, the most immediate effect of such modification is likely to be on the nutritional value (lysine is an EAA) and physical processing properties of the $\beta$-LG. Also, as for lactoferrin, these results highlight the need for sensitive tracking of modification during dairy food and ingredient processing, where retention of protein quality and function are key considerations for the final product (Joubran et al., 2013). The Lys107, Lys116, and Lys154 are likely to be the most useful $\beta$-LG sites for tracking Maillard modification during food processing.

Hydrothermal Redox Modifications. In addition to tracking Maillard modification in lactoferrin and $\beta-L G$, we characterized and tracked a range of other common protein redox modifications. These are summarized for lactoferrin in Table 4 and $\beta$-LG in Table 5 .

In terms of sensitivity to oxidation, although all AA residues can be oxidatively modified, typically the sulfur-containing residues cysteine and methionine are the most susceptible, followed by the aromatic residues, notably tryptophan and tyrosine, and then the cyclic residue, proline (Stadtman, 2006; Pattison et al., 2012).

Lactoferrin. We observed several lactoferrin sites susceptible to hydrothermally induced oxidation. Most modifications observed were deamidation or oxidation of cysteine or methionine, and no clear correlations were found to heating time and identification of potential peptide markers for tracking oxidation. In general, lactoferrin appears to be very robust to hydrothermal redox modification.

$\boldsymbol{\beta}$-Lactoglobulin. $\beta$-Lactoglobulin, on the other hand, appears to be significantly more susceptible to redox modification via hydrothermal insult. We found oxidation of Met23 and Met161 in the unheated protein samples, indicating that some baseline oxidative modification already existed in the samples. The Met161 is located within a peptide (MHIRL) that has been assigned putative anti-oxidant function (Hartmann and Meisel, 2007). Notable modifications characterized with heating included the oxidation of Cys82, Cys122, Cys135, Cys137, and Cys176 to cysteic acid. These cysteines are all involved in disulfide bonding in bovine $\beta$-LG (Cys82 $\leftrightarrow$ Cys176; Cys122↔Cys135 or Cys137; Kontopidis et al., 2004). Oxidation to cysteic acid is irreversible and this modification would therefore be expected to have a significant effect on the structure and physical properties, such as solubility of the protein. This is an interesting result, as circular dichroism measurements have shown that both the secondary and tertiary structure of $\beta$-LG start to change at approximately $50^{\circ} \mathrm{C}$ with abrupt changes around $65^{\circ} \mathrm{C}$ (Qi et al., 1997). The reason whey proteins form gels upon heating is believed to be due to the formation of disulfide bond networks. Irreversible cysteine oxidation would therefore be expected to reduce the amount of possible disulfide networking and increase the solubility of $\beta-\mathrm{LG}$.

We also characterized a range of different oxidative modifications in Trp35 and Trp77, particularly in samples heated for $168 \mathrm{~h}$. These included hydroxytryptophan, N-formylkynurenine (dioxidation product), and hydroxykynurenine (Dyer et al., 2006a). Hydroxykynurenine is an advanced oxidation product derived from tryptophan (Dyer et al., 2006b), and its characterization here across a range of the heattreated samples either with or without added lactose indicates that this particular residue was undergoing significant oxidative degradation. The modification of Trp35 is of particular significance as it is in a section of $\beta$-LG (WYSLAMAASDI), which has been assigned putative anti-oxidant function (Hartmann and Meisel, 
Table 5. Redox modifications observed in $\beta$-LG when heated at $55 \mathrm{C}$ for $0,24,48,96$, or $168 \mathrm{~h}$ with or without added lactose ${ }^{1}$

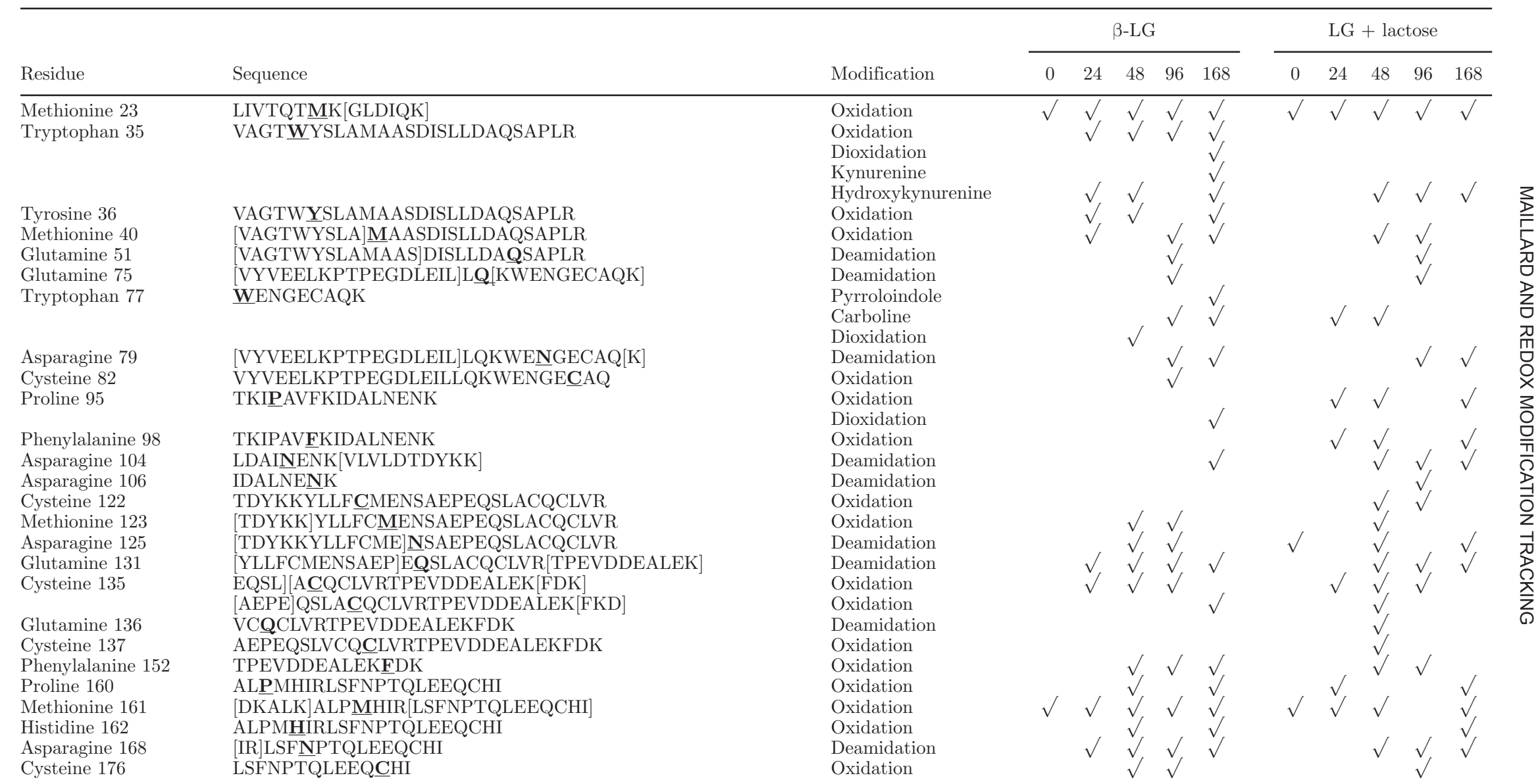

$\frac{1}{1 \sqrt{ } \text { means that the modification was found, and blank means that a modification was not found. Residues contained within square brackets represent extensions of the peptide that }}$ $\sqrt{ }$ means that the 
2007). The tryptophan residue-containing peptide VAGTWYSLAMAASDISLLDAQSAPLR appears to be a suitable marker peptide for tracking oxidative modification in $\beta-\mathrm{LG}$.

The range and number of modifications induced through heat treatment indicate that thermal modification could compromise the nutritional value of $\beta-\mathrm{LG}$, with significant modification observed in essential AA residue sites. We did not observe a significant difference in modification pattern between the samples treated with and without added lactose. We have previously shown that hydrothermal oxidation produces similar oxidation products to that induced by other forms of oxidative insult, such as photo-oxidation (Dyer et al., 2010; Grosvenor et al., 2010, 2011), and this was confirmed by the modification types observed in this study.

Figure 2 shows the mapped modifications observed with hydrothermal treatment within the primary structure of lactoferrin and $\beta$-LG. Comparing these 2 dairy proteins, it is notable that $\beta-\mathrm{LG}$ appears to be significantly more susceptible to modification with heating. Despite being a much smaller protein in terms of residue numbers and mass compared with lactoferrin (lactoferrin $80 \mathrm{kDa}$ versus $\beta$-LG $18 \mathrm{kDa}$ ), significantly more modification types and sites were observed and characterized. This may well relate to tertiary structural differences between the 2 whey proteins, with the compact globular structure of lactoferrin inhibiting unfolding of the protein and thereby offering a protective effect to internal AA residues (Baker and Baker,
2012). $\beta$-Lactoglobulin is also globular in its native state, but these results suggest that at least some denaturation has occurred during commercial extraction, which would expose more AA residues to modification. Another contributing factor may be the presence of Fe (II) ions within the lactoferrin structure, which can be oxidized to Fe (III) ions and therefore offer a sacrificial protective effect not available in $\beta$-LG.

The range and number of modifications induced through heat treatment as observed in our study indicate that thermal modification may compromise nutritional value. For lactoferrin particularly, given its high relative value and increasing use as a functional ingredient, these results are significant for future dairy foods. Maillard chemistries affect the color, flavor, digestibility, and nutritional value of food. The sensitivity of these sites to Maillard modification, as observed in our study, therefore has potentially important implications for processing applications where retention of this biological function and optimal protein quality is desired.

\section{CONCLUSIONS}

We used a redox proteomic approach to evaluate and map the AA residue side-chain modifications induced by heating bovine lactoferrin and $\beta$-LG with and without added lactose. Heating in the presence of lactose resulted in significant Maillard modification to lactoferrin, with Lys47 and Lys627 found to be particularly susceptible. The Lys47 is part of the bovine lactoferricin sequence and modification at this site may be

\section{$\underline{\text { Lactoferrin }}$}

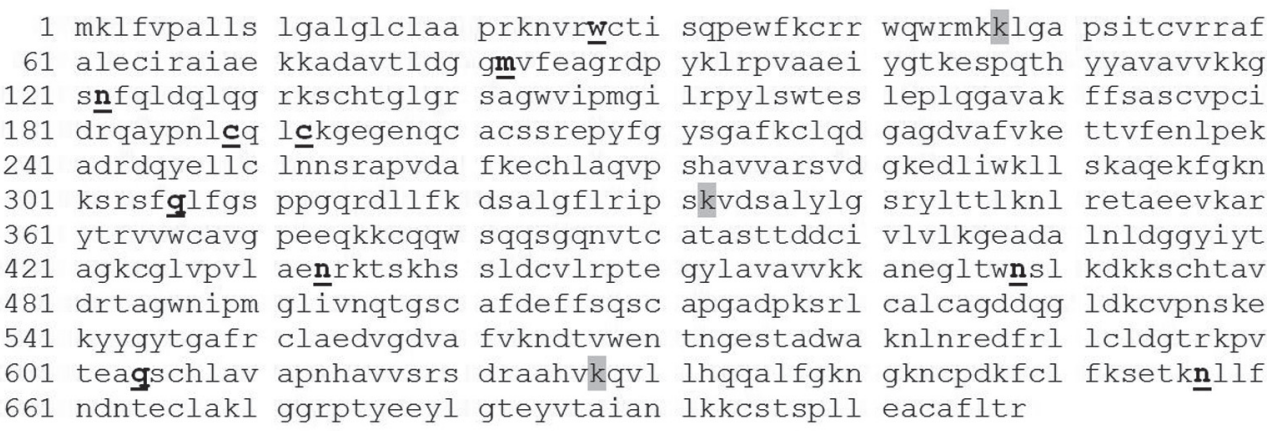

B-lactoglobulin

1 mkclllalal tcgaqalivt qtmkgldiqk vagtwyslam aasdisllda gsaplrvyve

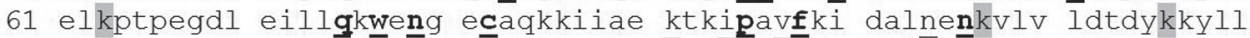
121 f 
significant with regard to the function of this bioactive peptide. Lactosylation was observed at Lys47, Lys329, and Lys627, and we characterized carboxymethylation for what we believe to be the first time at Lys47 and Lys627. On the other hand, lactoferrin appeared to be robust to hydrothermal insult, with relatively low levels of oxidative modification observed, even over heating times up to $168 \mathrm{~h}$ at $55^{\circ} \mathrm{C}$. We also characterized lactosylation and carboxymethylation sites in bovine $\beta$-LG. $\beta$-Lactoglobulin was more susceptible to significant oxidative modification under hydrothermal insult relative to lactoferrin, and some baseline oxidation was already evident, presumably induced during the purification preparation of the protein from milk.

\section{ACKNOWLEDGMENTS}

Funding for this project was provided through the AgResearch Capability Fund (Lincoln, New Zealand; A13591).

\section{REFERENCES}

Adlerova, L., A. Bartoskova, and M. Faldyna. 2008. Lactoferrin: A review. Vet. Med. (Praha) 53:457-468.

Aminlari, M., R. Ramezani, and F. Jadidi. 2005. Effect of Maillardbased conjugation with dextran on the functional properties of lysozyme and casein. J. Sci. Food Agric. 85:2617-2624.

Badoud, R., F. Hunston, L. B. Fay, and G. Pratz. 1990. Oxidative degradation of protein-bound Amadori products: Formation of $\mathrm{N}^{\varepsilon}$ (carboxymethyl)lysine and N-carboxymethyl amino acids as indicators of the extent of non-enzymatic glycosylation. Pages 79-84 in The Maillard Reaction. Birkhauser Verlag, Basel, Switzerland.

Baker, H. M., and E. N. Baker. 2012. A structural perspective on lactoferrin function. Biochem. Cell Biol. 90:320-328.

Brock, J. W. C., D. J. S. Hinton, W. E. Cotham, T. O. Metz, S. R. Thorpe, J. W. Baynes, and J. M. Ames. 2003. Proteomic analysis of the site specificity of glycation and carboxymethylation of ribonuclease. J. Proteome Res. 2:506-513.

Cerbulis, J., and H. M. Farrell Jr.. 1975. Composition of milks of dairy cattle. I. Protein, lactose, and fat contents and distribution of protein fraction. J. Dairy Sci. 58:817-827.

Czerwenka, C., I. Maier, F. Pittner, and W. Lindner. 2006. Investigation of the lactosylation of whey proteins by liquid chromatography-mass spectrometry. J. Agric. Food Chem. 54:8874-8882.

Dalsgaard, T. K., J. H. Nielsen, and L. B. Larsen. 2007. Proteolysis of milk proteins lactosylated in model systems. Mol. Nutr. Food Res. 51:404-414.

Davies, M. J. 1996. Protein and peptide alkoxyl radicals can give rise to C-terminal decarboxylation and backbone cleavage. Arch. Biochem. Biophys. 336:163-172.

Dyer, J. M., S. D. Bringans, and W. G. Bryson. 2006a. Characterisation of photo-oxidation products within photoyellowed wool proteins: Tryptophan and tyrosine derived chromophores. Photochem. Photobiol. Sci. 5:698-706.

Dyer, J. M., S. D. Bringans, and W. G. Bryson. 2006b. Determination of photo-oxidation products within photoyellowed bleached wool proteins. Photochem. Photobiol. 82:551-557.

Dyer, J. M., J. Plowman, G. Krsinic, S. Deb-Choudhury, H. Koehn, K. Millington, and S. Clerens. 2010. Proteomic evaluation and location of UVB-induced photomodification in wool. Photochem. Photobiol. Bol. Biol. 98:118-127.
Farrell, H. M. Jr., R. Jimenez-Flores, G. T. Bleck, E. M. Brown, J. E. Butler, L. K. Creamer, C. L. Hicks, C. M. Hollar, K. F. Ng-KwaiHang, and H. E. Swaisgood. 2004. Nomenclature of the proteins of cows' milk-Sixth revision. J. Dairy Sci. 87:1641-1674.

Fogliano, V., S. M. Monti, A. Visconti, G. Randazzo, A. M. Facchiano, G. Colonna, and A. Ritieni. 1998. Identification of a $\beta$-lactoglobulin lactosylation site. Biochim. Biophys. Acta Protein Struct. Mol. Enzymol. 1388:295-304.

Friedman, M. 1999. Chemistry, biochemistry, nutrition, and microbiology of lysinoalanine, lanthionine, and histidinoalanine in food and other proteins. J. Agric. Food Chem. 47:1295-1319.

Gifford, J. L., H. N. Hunter, and H. J. Vogel. 2005. Lactoferricin: A lactoferrin-derived peptide with antimicrobial, antiviral, antitumor and immunological properties. Cell. Mol. Life Sci. 62:2588-2598.

Grosvenor, A. J., J. D. Morton, and J. M. Dyer. 2010. Profiling of residue-level photo-oxidative damage in peptides. Amino Acids 39:285-296.

Grosvenor, A. J., J. D. Morton, and J. M. Dyer. 2011. Proteomic characterisation of hydrothermal redox damage. J. Sci. Food Agric. 91:2806-2813.

Guyomarc'h, F., F. Warin, D. Donald Muir, and J. Leaver. 2000. Lactosylation of milk proteins during the manufacture and storage of skim milk powders. Int. Dairy J. 10:863-872.

Hartmann, R., and H. Meisel. 2007. Food-derived peptides with biological activity: From research to food applications. Curr. Opin. Biotechnol. 18:163-169.

Hoek, K. S., J. M. Milne, P. A. Grieve, D. A. Dionysius, and R. Smith. 1997. Antibacterial activity in bovine lactoferrin-derived peptides. Antimicrob. Agents Chemother. 41:54-59.

Hurrell, R. F., P. A. Finot, and J. E. Ford. 1983. Storage of milk powders under adverse conditions 1. Losses of lysine and other essential amino acids as determined by chemical and microbiological methods. Br. J. Nutr. 49:343-354.

Jing, H., and D. D. Kitts. 2004. Chemical characterization of different sugar-casein Maillard reaction products and protective effects on chemical-induced cytotoxicity of Caco-2 cells. Food Chem. Toxicol. 42:1833-1844.

Joubran, Y., A. Mackie, and U. Lesmes. 2013. Impact of the Maillard reaction on the antioxidant capacity of bovine lactoferrin. Food Chem. 141:3796-3802.

Joubran, Y., A. Moscovici, and U. Lesmes. 2015. Antioxidant activity of bovine alpha lactalbumin Maillard products and evaluation of their in vitro gastro-duodenal digestive proteolysis. Food Funct. 6:1229-1240.

Kontopidis, G., C. Holt, and L. Sawyer. 2004. Invited review: $\beta$-lactoglobulin: Binding properties, structure, and function. J. Dairy Sci. 87:785-796.

Meltretter, J., S. Seeber, A. Humeny, C.-M. Becker, and M. Pischetsrieder. 2007. Site-specific formation of Maillard, oxidation, and condensation products from whey proteins during reaction with lactose. J. Agric. Food Chem. 55:6096-6103.

Meyer, B., F. Baum, G. Vollmer, and M. Pischetsrieder. 2012. Distribution of protein oxidation products in the proteome of thermally processed milk. J. Agric. Food Chem. 60:7306-7311.

Moore, S. A., B. F. Anderson, C. R. Groom, M. Haridas, and E. N. Baker. 1997. Three-dimensional structure of diferric bovine lactoferrin at $2.8 \AA$ resolution. J. Mol. Biol. 274:222-236.

Moscovici, A. M., Y. Joubran, V. Briard-Bion, A. Mackie, D. Dupont, and U. Lesmes. 2014. The impact of the Maillard reaction on the in vitro proteolytic breakdown of bovine lactoferrin in adults and infants. Food Funct. 5:1898-1908.

Pattison, D. I., A. S. Rahmanto, and M. J. Davies. 2012. Photo-oxidation of proteins. Photochem. Photobiol. Sci. 11:38-53.

Poulsen, M. W., R. V. Hedegaard, J. M. Andersen, B. de Courten, S. Bügel, J. Nielsen, L. H. Skibsted, and L. O. Dragsted. 2013. Advanced glycation endproducts in food and their effects on health. Food Chem. Toxicol. 60:10-37.

Qi, X. L., C. Holt, D. McNulty, D. Clarke, S. Brownlow, and G. R. Jones. 1997. Effect of temperature on the secondary structure of $\beta$-lactoglobulin at $\mathrm{pH} 6.7$, as determined by $\mathrm{CD}$ and IR spec- 
troscopy: A test of the molten globule hypothesis. Biochem. J. 324:341-346.

Renzone, G., S. Arena, and A. Scaloni. 2015. Proteomic characterization of intermediate and advanced glycation end-products in commercial milk samples. J. Proteomics 117:12-23.

Stadtman, E. R. 2006. Protein oxidation and aging. Free Radic. Res. 40:1250-1258.

Tantoush, Z., D. Stanic, M. Stojadinovic, J. Ognjenovic, L. Mihajlovic, M. Atanaskovic-Markovic, and T. Cirkovic Velickovic. 2011. Digestibility and allergenicity of $\beta$-lactoglobulin following laccasemediated cross-linking in the presence of sour cherry phenolics. Food Chem. 125:84-91.

Thomsen, M. K., L. Lauridsen, L. H. Skibsted, and J. Risbo. 2005. Temperature effect on lactose crystallization, Maillard reactions, and lipid oxidation in whole milk powder. J. Agric. Food Chem. 53:7082-7090.

Tomita, M., H. Wakabayashi, K. Shin, K. Yamauchi, T. Yaeshima, and K. Iwatsuki. 2009. Twenty-five years of research on bovine lactoferrin applications. Biochimie 91:52-57.

Van Boekel, M. A. J. S. 1998. Effect of heating on Maillard reactions in milk. Food Chem. 62:403-414.

Villaverde, A., and M. Estévez. 2013. Carbonylation of myofibrillar proteins through the Maillard pathway: Effect of reducing sugars and reaction temperature. J. Agric. Food Chem. 61:3140-3147.

Xu, X.-B., F. Ma, S.-J. Yu, and Y.-G. Guan. 2013. Simultaneous analysis of $\mathrm{N} \varepsilon$-(carboxymethyl)lysine, reducing sugars, and lysine during the dairy thermal process. J. Dairy Sci. 96:5487-5493. 